\title{
Death and seniors' health dominate CMA annual meeting
}

A preoccupation with death and senior's health permeated the Canadian Medical Association annual general meeting in Calgary, Alberta last month. Nearly 300 delegates representing the CMA's 78000 member physicians approved a number of motions, but deferred a vote on arguably the most controversial.

Delegates grappled with the ethical, legal and medical implications of assisting in the deaths of suffering patients. But they defeated a motion that asked the association to urge "all relevant levels of government to conduct a large-scale public consultation to consider the recognition of medical aid in dying as appropriate end-of-life care."

Instead, the delegates referred the issue of medically assisted death, back to the CMA's board for further deliberation.

The motion was triggered by Quebec's proposed legislation that would allow doctors to comply with patients' requests for help in supplying life-ending medication under particular circumstances, such as when a patient has a terminal illness and suffers intractable physical or emotional pain with no hope of relief. The Quebec legislature will begin public hearings on Bill 52, An Act respecting end-of-life care, this fall.

Dr. Laurent Marcoux, the president of the Quebec Medical Association, introduced the motion and urged his colleagues to take a leadership role in moving the discussion about assistance in dying, as part of end-of-life care, to the national stage.

Other doctors, however, particularly those involved in palliative care, objected to their national association undertaking that role.

The decision leaves intact the CMA's 2007 policy, which states that doctors should not participate in euthanasia or assisted suicide. The policy recognizes, however, that it is the prerogative of Canadian society to change the laws regarding assisted suicide and euthanasia.

Although the issue of medically

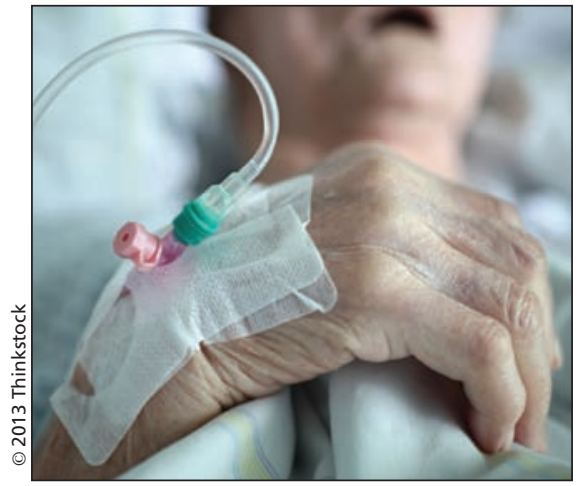

Delegates at the CMA annual meeting referred the issue of medically assisted death back to the CMA's board for deliberation.

assisted death split delegates, there was widespread endorsement for another motion calling for a national strategy to provide long-term health care for seniors. The motion urged all levels of government to cooperate in creating the strategy, but CMA then-President Dr. Anna Reid said it should be a federal priority.

The motion concurs with public opinion, according to the results of an Ipsos Reid survey of 1000 Canadian adults, featured in CMA's 13th Annual National Report Card on Health Care. In the survey, $85 \%$ of respondents agreed that Canada needs a comprehensive health care strategy for seniors and $78 \%$ said the federal government has an important role to play in developing a national seniors' care strategy.

A pre-meeting session turned doctor's attention to the need for advancecare plans. Many doctors are reluctant to initiate discussions about end-of-life planning with their patients - or to make their own advanced-care plans, experts in the advanced-care field told physicians.

They are concerned that they will make their patients uncomfortable, or that they don't know enough to guide their patients, says Sharon Baxter, executive director of the Canadian Hospice Palliative Care Association.

Advanced care planning increases the quality of life of dying patients, improves the experience of family members and decreases health care costs, Baxter told the doctors. But although most professionals support the idea of advanced care planning, the majority do not engage in it, she said.

\section{Physician supply}

Canada's doctors also called for a comprehensive national health care resources strategy to better meet emerging needs. "The goal is to find the right number, mix and distribution of physicians," said Dr. Jesse Pasternak, chair of the Canadian Association of Internes and Residents' health human resources committee.

The CMA has been struggling for years with how best to assure that the supply of graduating doctors meets the needs of the population. Part of the problem in coordinating physician supply and demand is that planning and governance fall under the jurisdiction of the provinces, without federal oversight.

\section{Health minister}

Canada's new Health Minister, Rona Ambrose, who addressed delegates on Aug. 19, promised to be collaborative and communicative. Ambrose said she would listen to and work with physicians, and have an open-door policy for discussing the nation's pressing health issues, particularly family violence and improving health care for First Nations and Inuit Canadians.

Ambrose also reiterated her government's commitment to a strong, publicly funded medicare system, "guided by the Canada Health Act," although she also stressed the need to improve productivity and find efficiencies.

According to a CMA-commissioned Ipsos Reid survey, Canadians are less than satisfied with the federal role. Respondents were asked to assign a letter grade to their perception of how well the federal government has performed on the health care front: only $7 \%$ awarded the government an A, 33\% gave it a B, 35\% awarded a C and $19 \%$ assigned a failing grade. - Laura Eggertson, CMAJ

CMAJ 2013. DOI:10.1503/cmaj.109-4581 